\title{
A feasibility trial of parent HPV vaccine reminders and phone-based motivational interviewing
}

Stephanie A. S. Staras ${ }^{1,2^{*}}$ (D), Eric Richardson ${ }^{1}$, Lisa J. Merlo ${ }^{2,3}$, Jiang Bian ${ }^{1}$, Lindsay A. Thompson 1,2,4, Janice L. Krieger ${ }^{5}$, Matthew J. Gurka ${ }^{1,2}$, Ashley H. Sanders ${ }^{1,2}$ and Elizabeth A. Shenkman 1,2

\begin{abstract}
Background: We assessed the feasibility and acceptability of a sequential approach of parent-targeted HPV vaccine reminders and phone-based Motivation Interviewing (MI).

Methods: In 2016, we selected all 11- to 12-year-old boys and girls seen in one clinic whose vaccine records did not include the HPV vaccine ( $n=286$ ). By gender, we individually randomized parents of adolescents to an interactive text message (74 girls and 45 boys), postcard reminder (46 boys and no girls because of previously demonstrated efficacy), or standard care group (75 girls and 46 boys). Reminders were sent with medical director permission and a HIPAA waiver. Two months after reminders, among the adolescents whose vaccine records still did not include the HPV vaccine, we selected a gender-stratified random sample of 20 parents for phone-based MI. We assessed the percentage of deliverable messages, the percentage of parents' responding to the interactive text message, parent acceptability of receiving a text message, and Ml parent responsiveness and interviewer competence (MI Treatment Integrity Coding system).

Results: Nearly all messages were deliverable ( $98 \%$ of postcards and $74 \%$ of text messages). Six of the 88 parents (7\%) receiving text messages scheduled an appointment through our interactive system. The acceptability survey response rate was 37\% (38/102). Respondents were favorable toward vaccine reminders for all parents (82\%). Among 20 sampled parents, 17 were reached by phone of whom 7 completed Ml, 4 had or were getting the HPV vaccine for their child, and 5 expressed disinterest. Across the $7 \mathrm{Ml}$ calls, the interviewer was rated 100\% Ml adherent and scored an average 4.19 rating for Global Spirit.

Conclusion: Without providing explicit consent to receive vaccine-related messages, parents nonetheless found postcards and interactive text messages acceptable. Centralizing Ml to phone calls with trained staff was acceptable to parents and resulted in highly Ml-adherent interviews.
\end{abstract}

Keywords: Motivational interviewing, HPV vaccine, Text messaging, Feasibility, Acceptability

\footnotetext{
* Correspondence: sstaras@ufl.edu

${ }^{1}$ Department of Health Outcomes and Biomedical Informatics, College of

Medicine, University of Florida, Gainesville, FL, USA

${ }^{2}$ The Institute for Child Health Policy, College of Medicine, University of

Florida, Gainesville, FL, USA

Full list of author information is available at the end of the article
}

(c) The Author(s). 2021 Open Access This article is licensed under a Creative Commons Attribution 4.0 International License, which permits use, sharing, adaptation, distribution and reproduction in any medium or format, as long as you give appropriate credit to the original author(s) and the source, provide a link to the Creative Commons licence, and indicate if changes were made. The images or other third party material in this article are included in the article's Creative Commons licence, unless indicated otherwise in a credit line to the material. If material is not included in the article's Creative Commons licence and your intended use is not permitted by statutory regulation or exceeds the permitted use, you will need to obtain permission directly from the copyright holder. To view a copy of this licence, visit http://creativecommons.org/licenses/by/4.0/ The Creative Commons Public Domain Dedication waiver (http://creativecommons.org/publicdomain/zero/1.0/) applies to the data made available in this article, unless otherwise stated in a credit line to the data. 


\section{Background}

Despite the potential for the human papillomavirus (HPV) vaccine to prevent 31,200 cancer cases each year in the United States [1], only $73 \%$ of female and $70 \%$ of male 13- to 17-year-olds have initiated the HPV vaccine series (received of $\geq 1$ dose) with some states having as few as $49 \%$ of adolescents initiating [2]. Likely the most effective way to increase HPV vaccination is for adolescents and their parents to receive clear and strong recommendations from their physician [3-7]. Within a well child visit, when vaccines are most commonly recommended and administered, the American Academy of Pediatrics recommends covering over 25 topics within the typically allotted 15 to $20 \mathrm{~min}$ [8-10]. Therefore, understandably, physicians report limited time to probe and discuss parental hesitations about the HPV vaccine $[3,11]$. The time burden on physicians of addressing $\mathrm{HPV}$ vaccination could be eased with interventions that occur prior to and between clinic visits aimed at prompting clinic visits among acceptors, priming questioning parents with educational information, and addressing the specific concerns of more hesitant parents.

A common pre-clinic visit intervention for parents is sending vaccine reminders (e.g., autodialed phone calls, text-messages, or mailed postcards) that alert parents of recommended vaccines. Reminders are an effective and recommended strategy to increase vaccination including HPV vaccination [12-15]. Specifically for adolescent vaccination, however, reminders produce moderate increases in vaccination rates: a Cochrane review found only a $7 \%$ increase in vaccination rates from reminders across 10 studies with 30,868 participants [15-17]. Preliminary evidence suggests reminder effectiveness may be boosted with strategies like allowing parents to request a clinic call back, including educational information, and combining reminders with other interventions such as phone calls or navigator home visit [12, 13, 15, 18-21].

One well-established strategy to encourage individuals to adopt healthier behaviors, that to our knowledge, has not been applied in advance of clinic visit for vaccines, is Motivational Interviewing (MI) [22-27]. MI is a patientcentered, collaborative approach that uses specific skills (e.g. reflections, affirmations, open-ended questions) to enhance patients' internal motivation to change by exploring resistance or ambivalence [28]. Several studies have taught physicians MI techniques as a way to improve communication with their patients regarding smoking, obesity, and even HPV vaccine hesitation [29-31]. The effectiveness of physician-delivered MI for vaccination as a component of primary care is limited by two primary challenges. First, the MI style conflicts with the tendency of many physicians to primarily give patients advice. Second, conducting MI proficiently is difficult, requires intensive training, and may require more time than a physician believes she or he can spend during a clinical visit [31-34]. However, there is evidence that MI interventions can be conducted successfully by a non-physician outside the typical clinic visit. For example, to increase the reach of an MI intervention for substance use disorder, MI was performed over the telephone by trained clinicians outside of an office-based visit [35].

Before the effectiveness of a pre-clinic intervention can be tested in a larger randomized control trial, an evaluation of fit must be conducted. According to Proctor et al., feasibility and acceptability are two of the three most important ways of determining how well an intervention fits within a particular setting [36]. Following best practices for conducting pilot studies [37], we evaluated the acceptability and feasibility of a two-phased, parent-targeted intervention to increase HPV vaccine initiation among 11- to 12-year-olds between May and November 2016. In the first phase, we sent reminders to all parents attending a clinic by capitalizing on the authority of medical clinics to inform parents of recommended services. The reminder (postcard or text message) included educational information about the HPV vaccine identified as most relevant to parents in North Central Florida - cancer prevention and safety [5]. In the text messages, we streamlined the call-toaction by including an interactive scheduling system. In the second phase, a sample of parents who did not have their child receive the HPV vaccine following the reminders were invited to phone-based MI sessions with a trained psychologist. We evaluated acceptability and feasibility regarding (1) delivery of reminder messages, (2) parent acceptability of reminders and phone-based MI, (3) interviewer MI proficiency.

\section{Methods}

\section{Study population}

Using one North-Central Florida, academic, primary care clinic's electronic health record (EHR) data, we identified all 11- to 12-year-old girls and boys (date of birth $7 / 2 / 2003$ to $4 / 1 / 2005$ ) who had visited the clinic in the preceding year $(3 / 1 / 2015$ to $2 / 29 / 2016)$. Among the 548 adolescents, we selected the 325 adolescents whose immunization history did not include the HPV vaccine as of April 14, 2016 in the clinic's EHR billing and immunization history: HPV quadrivalent vaccine Gardasil, HPV-9 valent vaccine Gardasil 9, or HPV bivalent vaccine Cervarix. To find additional vaccine records, we matched the adolescents to the enrollment records for the Florida Children's Health Insurance Program (CHIP) and Medicaid Programs of Managed Care and Fee for Service using two algorithms: (1) date of birth, last name, and first four letters of first name or (2) date of birth, first two letters of last name, and city of residence. With this strategy, we matched 280 records including 
97\% of the 234 listed as Medicaid insured in the EHR. We eliminated the 39 adolescents who had Medicaid or CHIP claims for the HPV vaccine (Current Procedural Terminology Codes 90,649, 90,650, and 90,651) reported by May 4th, 2016. The final study population was 286 adolescents (137 boys and 149 girls).

\section{Study design}

We used a two-phased, factorial design with simple randomization to assign parents to interventions (Fig. 1). Parents of boys were equally randomized into one of three conditions: postcard $(n=46)$, text messaging $(n=$ $45)$, and standard of care $(n=45)$. Due to our previous study demonstrating the efficacy of postcards among girls [38], we randomized parents of girls to two conditions: text messaging $(n=74)$ and standard of care $(n=$ 75). To test the feasibility of a one-time, phone-based MI session among parents non-responsive to reminders, we selected a gender-stratified random sample of 20 adolescents who did not have HPV vaccine records by 60 days after the reminder (July 11, 2016) that were available in the EHR by July 29, 2016 or in Medicaid claims by August 9, 2016.

\section{Intervention components}

\section{Postcard and text reminders}

To send the messages without acquiring explicit permission from the parents, we sent our postcard and textmessage reminders under the authority of the medical director of the primary care clinic and obtained a Health Insurance Portability and Accountability Act waiver of authorization. Moreover, messages were applicable to all 11- to 12-year-olds and did not reference the child's vaccine record.

Based on our previous effective postcards among girls [38], our postcard and text messages included key words ("protect," "safe," and "free"), were sent in English and Spanish, and were personalized to include the first name of the child in the message. Based on our previous postcard strategy [38], we revised our boys' postcard to include a picture of an African American mother and son and the phrases "Protect Your Son from Cancer" and "Get the Facts." The six-by-eight inch, full-color postcards included a web address and phone number for more information. For each boy, we obtained addresses from the EHR (primary) or Medicaid enrollment (secondary). Prior to mailing, we updated addresses with the National Change of Address Database. On May 18, 2016, we sent one postcard to the boys' parents or guardians via first class mail with return service requested.

Also, on May 18, 2016, we sent text messages to the phone number in the EHR (primary) or Medicaid enrollment (secondary) from the same phone number and vendor as the clinic's appointment reminder system. Text messages said: "Did you know you can protect [insert child's first name] from certain cancers? The HPV vaccine is safe, free, and easy. Reply Yes to have [insert child's first name]'s doctor's office call you." If the parent replied "Yes," they received a reply stating that the clinic staff would call within two business days to schedule an appointment. Clinic schedulers called text responders. We looked for and sent text messages to alternative

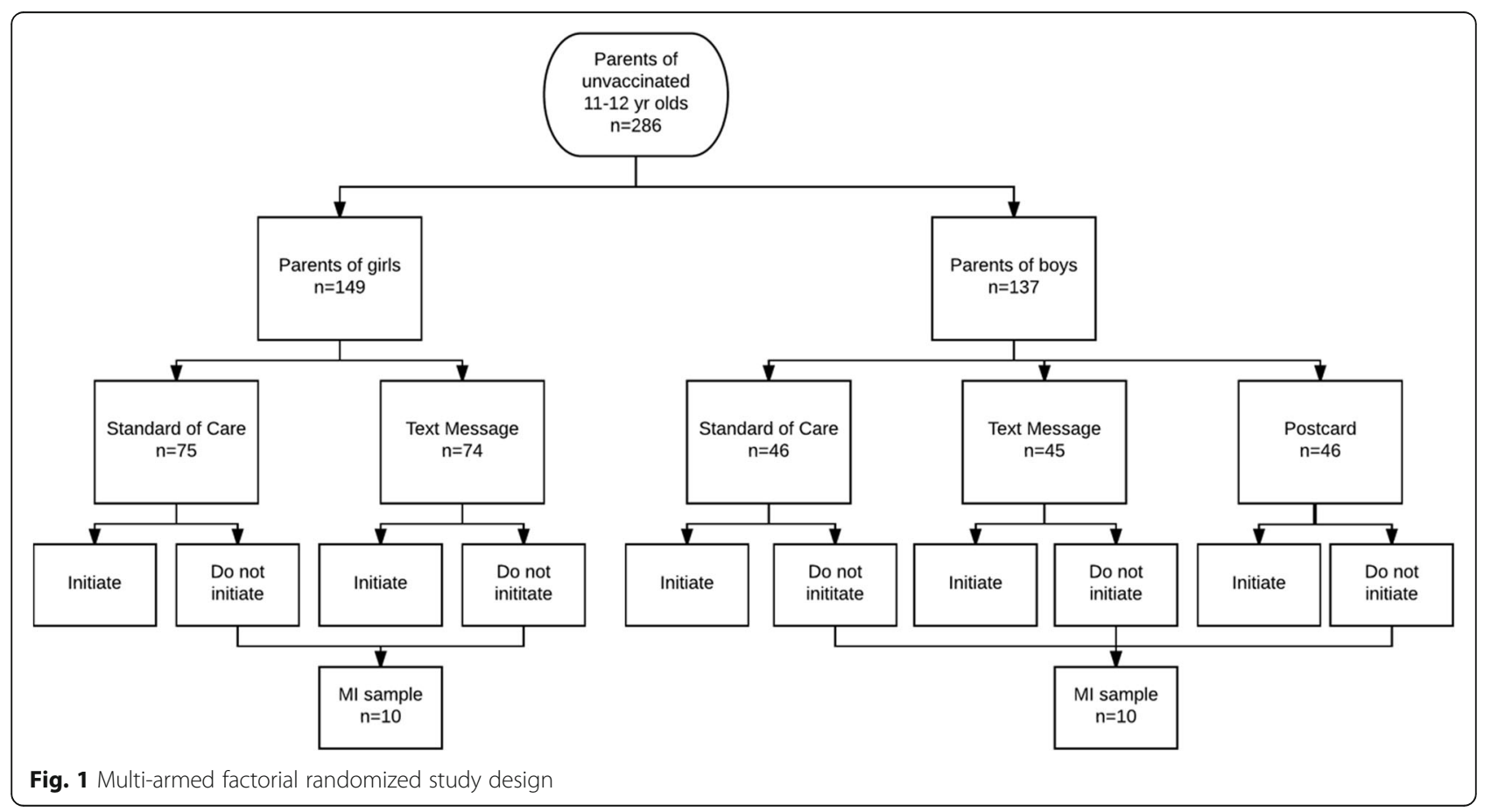


phone numbers when initial text messages were nondeliverable.

\section{MI phone calls}

On August 22, 2016, we mailed invitation letters to inform the parents of the 20 selected adolescents of the upcoming MI calls. Between August 25, 2016 and September 13, 2016, we attempted to call parents at the phone number in the EHR at various times of the day, for up to ten calls per number. A licensed clinical psychologist and member of the Motivational Interviewing Network of Trainers (LM) conducted and audio recorded all phone calls. Following parent consent, the psychologist guided the parent in a conversation designed to help them make a fully-informed decision about vaccinating their child for HPV with open-ended questions, reflective listening, and a focus on individual concerns and autonomy support [23, 24, 39]. An approximate conversation guide led the interviewer through establishing a relationship with the parent in a general discussion about vaccines, providing HPV vaccine information, answering questions, and aiding the parent in setting a personal goal regarding the HPV vaccine for their child, if appropriate (see Supplement A). The study team provided the psychologist with information to address commonly asked questions about the HPV vaccine. Mobile phone minute fee reimbursement was available for participants upon request.

\section{Feasibility and acceptability measures Reminders}

We assessed the acceptability and feasibility of reminders in four ways. First, we assessed whether messages were delivered (non-returned postcards or confirmed deliverable text messages). Second, we assessed parents' response to messages by tracking the number of requests that messages stop, calls to the phone number provided on the postcard for more information, and unique hits to the website provided on the postcard. Third, we assessed the interactive scheduling component by tracking the percentage of parents that responded yes and the outcomes of returned calls. For each responding parent, clinic staff tracked contact attempts, scheduled appointments, and HPV-related questions asked. Fourth, we sent a brief one-page acceptability survey to up to 50 randomly-selected parents within each of three groups (text message responders, text message non-responders, and postcard recipients). Questions included parents' recall of the reminder, opinions about the reminder, actions taken upon receiving the reminder, and expectations and experiences with interactive scheduling (if applicable) (see supplement B). We sent each parent selected for the survey a notification postcard (June 14, 2016), a survey with a $\$ 10$ cash incentive via FedEx (June $23,2016)$, and randomized non-responders equally to an additional mailed survey or a texted online survey link (July $28,2016)$.

\section{MI}

We assessed phone-based MI acceptability and feasibility by parent participation rates and behavioral coding of transcribed interviews. A trained MI coder independent from the study team used the MI Treatment Integrity (MITI) Coding manual 3.1 to assign each interview a score for global ratings and MI techniques [23, 24, 39]. Particularly, in pilot studies, using one MI coder is typical for MITI scoring [40-43]. The global ratings capture the holistic performance of the interviewer and reflect evocation, collaboration, autonomy/support, direction and empathy. Each global rating is coded on a scale of 1 to 5 (1=low and 5=high). Additionally, a global spirit score is the calculated average of the global ratings for evocation, collaboration and autonomy/support [44]. A global spirit score of 3.5 is considered beginner proficiency and $\geq 4$ is considered to be competent. MI techniques are measured with counts of instances of an interviewer's behavior for important skills: giving information (e.g. provide feedback, educational material or explaining an idea), questions (open vs. closed questions), reflections (simple vs. complex), and MI adherence/MI non-adherence. Summary scores are created for each category by calculating ratios of ideal versus overall behavior (e.g. the percentage of questions that are open-ended). We used the proficiency and competency cutoff scores recommended in the MITI 3.0 as benchmarks.

\section{Statistical analysis}

Because this was a pilot study, we focused analysis on descriptive statistics and frequencies of the process measures and MITI scores. Following the CONSORT guidelines for pilot and feasibility studies [37], we did not perform any formal hypothesis testing for effectiveness. Analysis was conducted with SAS 9.4 (SAS Institute Inc., Cary, NC).

\section{Results \\ Feasibility of HPV vaccine reminders}

The majority of messages were delivered and acceptable to parents. Postcards were delivered to 98\% (45/46) of parents of boys. We confirmed delivery of text messages to the listed phone numbers for $80 \%(36 / 45)$ of parents of boys and 70\% (52/74) of parents of girls. Among parents for whom text messages were confirmed deliverable, $8 \%(n=7)$ requested messages stop. One parent called the number on the postcard to ask where they could get the HPV vaccine. Within the 6 months following the messaging, we had 213 unique visits to the website listed on the postcard. Most visitors only saw the home page, but each of our six topical links received 30 to 40 views. 
For the interactive scheduling component, $7 \%(n=6)$ of parents for whom we confirmed delivery of the text message replied that they would like the clinic to call to schedule an appointment. All were called within 2 business days of replying to the text and 83\% (5/6) were reached on the first attempt. All responding parents scheduled an appointment and 66\% (4/6) scheduled an appointment the day the text message was sent.

\section{Acceptability of HPV vaccine reminders}

We sent an acceptability survey to the 45 parents who received our postcard, the six parents who responded to the text message, and a random sample of 50 parents who did not respond to deliverable text messages. The overall survey response rate was 37\% (38 /102) with returned completed surveys from 19 parents who received postcards, one parent who responded to the text message, and 18 parents who did not respond to a deliverable text message. The vast majority $(82 \%)$ of the respondents agreed that all parents should receive reminders about the HPV vaccine (Table 1). Among the $55 \%(21 / 38)$ of parents who reported remembering receiving either a text or postcard message, 100\% agreed that the reminders were easy to understand and that they trusted the information provided. A majority of parents liked receiving the reminders (80\%). Importantly, over half of the parents (62\%) reported taking some action after receiving the reminders, such as calling their doctor, speaking to their child, or speaking to a friend or family member. The majority of parents recalled that the reminders included information on the HPV vaccine benefits (86\%) and safety (76\%).
Feasibility and acceptability of phone-based motivational interviewing

Among the 20 randomly selected parents, the interviewer was able to reach 17 (85\%). This required an average of 4 attempts (range $=1-10$ ). MI was completed with 7 parents (35\%). Among the 10 parents who were contacted but did not participate in MI, four reported they had already had their child receive or were trying to get the HPV vaccine, three expressed general disinterest, one expressed disinterest in HPV specifically, one hung up during the description, and one said to call back, but never answered again. MI calls lasted between 3 to $27 \mathrm{~min}$ (average length $=10: 47 \mathrm{~min}$ ). During the goal setting portion of the seven MI sessions, one parent reported she already had her child receive the HPV vaccine, one parent described her opposition to all vaccines, one parent wanted to conduct additional research before deciding, and four set a goal to get the HPV vaccine for their child during his or her next preventive visit. None of the contacted parents complained about the call.

\section{Proficiency of phone-based motivational interviewing}

Across calls, the interviewer competently followed the principles of MI indicated by an average Global Spirit Rating above 4 (score $=4.19$, standard deviation $=0.50)$ (Table 2). The interviewer displayed proficiency for each global rating score with an average over 3.5. Scores for four of the five global metrics were above 4 demonstrating competency. The interviewer scored a 5 on direction indicating the interviewer focused the conversation on the HPV vaccine and selectively reinforced discussion about the HPV vaccine. Using open questions for $56 \%$ of

Table 1 Acceptability of messages among 38 responding parents

\begin{tabular}{|c|c|c|c|}
\hline & $\begin{array}{l}\text { Postcard } \\
\text { N (\%) }\end{array}$ & $\begin{array}{l}\text { Text Message } \\
\mathrm{N}(\%)\end{array}$ & $\begin{array}{l}\text { Total } \\
\text { N (\%) }\end{array}$ \\
\hline Total & 19 & 19 & 38 \\
\hline All parents should receive a reminder & $15(79 \%)$ & $16(84 \%)$ & $31(82 \%)$ \\
\hline Remembered receiving message & $12(63 \%)$ & $9(47 \%)$ & $21(55 \%)$ \\
\hline Reminders were easy to understand & $12(100 \%)$ & $9(100 \%)$ & $21(100 \%)$ \\
\hline Trusted information on reminders & $12(100 \%)$ & $9(100 \%)$ & $21(100 \%)$ \\
\hline Liked receiving the reminders & $9(75 \%)$ & $8(89 \%)$ & $17(81 \%)$ \\
\hline \multicolumn{4}{|l|}{ Reaction to message } \\
\hline Any conversations or information seeking & $7(63 \%)$ & $6(67 \%)$ & $13(62 \%)$ \\
\hline Spoke with your child about the HPV vaccine & $2(17 \%)$ & $3(33 \%)$ & $5(24 \%)$ \\
\hline Looked up the HPV vaccine on the Internet & $3(25 \%)$ & $3(33 \%)$ & $6(29 \%)$ \\
\hline Spoke with friends or family or read about it & $2(17 \%)$ & $0(0 \%)$ & $2(10 \%)$ \\
\hline \multicolumn{4}{|l|}{ Believed message told about HPV vaccine } \\
\hline Benefits & $11(92 \%)$ & $7(77 \%)$ & $18(86 \%)$ \\
\hline Costs & $6(50 \%)$ & $6(67 \%)$ & 12 (57\%) \\
\hline Safety & 10 (83\%) & $6(67 \%)$ & 16 (76\%) \\
\hline
\end{tabular}


Table 2 MITI codes for seven MI phone calls regarding HPV vaccination

\begin{tabular}{lllll}
\hline & Average & Standard Deviation & Proficiency Score & Competency Score \\
\hline Length (minutes: seconds) & $10: 47$ & $8: 15$ & & $\geq 3.5$ \\
Global Spirit rating (1 to 5) & 4.19 & 0.50 & & $\geq 4$ \\
Global Ratings (1 to 5) & & & $\geq 3.5$ & $\geq 4$ \\
Evocation & 3.86 & 0.69 & $\geq 3.5$ & $\geq 4$ \\
Collaboration & 4.43 & 0.53 & $\geq 3.5$ & $\geq 4$ \\
Autonomy /Support & 4.29 & 0.49 & $\geq 3.5$ & $\geq 4$ \\
Direction & 5 & 0 & $\geq 3.5$ & $\geq 4$ \\
Empathy & 4.14 & 0.38 & $\mathrm{~N} / \mathrm{A}$ & $\mathrm{N} / \mathrm{A}$ \\
MI Techniques & & & $\geq 40 \%$ & $\geq 50 \%$ \\
Giving Information & 2.29 & 2.06 & $>50 \%$ & $>70 \%$ \\
Percent of Complex Reflections & $25 \%$ & $21 \%$ & $\geq 1$ & $\geq 2$ \\
Percent Open Questions & $56 \%$ & $14 \%$ & $\geq 90 \%$ & $100 \%$ \\
Reflection to Question Ratio & 0.68 & 0.17 & 0 & \\
\% Ml Adherent & $100 \%$ & & & \\
\hline
\end{tabular}

the questions, she showed interviewer proficiency (> $50 \%$ ). The interviewer scored below proficiency for percentage of complex reflections and the reflection to question ratio. Upon review, it became apparent that a number of reflections were "spoiled" by intonation, resulting in them being coded as closed-ended questions. The interviewer performed competently for adhering to MI principles $100 \%$ of the time.

\section{Discussion}

Among parents of 11 - to 12-year-olds attending a primary care clinic, we demonstrated the feasibility and acceptability of our sequential approach of parent-targeted HPV vaccine reminder messages. Our phone-based MI was acceptable to parents and feasible to conduct with a MINT trained professional. By and large, parents received and responded positively to vaccine reminders that they had not explicitly consented to receive. Nearly one out of ten parents scheduled clinical appointments by using our interactive text message system. Phone-based MI was conducted without complaints and performed competently with participating parents. A larger trial is warranted to test the effectiveness of the conjunctive use of text messaging and phone-based MI as pre-visit interventions to boost HPV vaccination rates without placing additional burden on physicians.

Despite not consenting to receive reminders, parents did not seem to find the contacts from the research team objectionable. We did not receive any complaints, and we received few opt-out requests from parents. While it is common that explicit consent is not collected for reminders for other vaccines, many HPV vaccine reminder studies have used explicit parent consent to receive vaccine reminders $[17,18,45,46]$. Thus, many interventions on HPV vaccine are limited to addressing HPV vaccine completion. By demonstrating the acceptability of parent reminders without explicit consent in a general pediatric setting in the southern United States, future trials can test the effectiveness of personalized messages to increase HPV vaccine initiation. Additionally, consistent with parents' endorsement of text reminders for infant vaccines [47], the $37 \%$ of parents who responded to our survey were overwhelmingly positive about the personalized reminders. The low response rate to the acceptability survey leaves room for potential non-response bias and potentially reduces generalizability to our target population. Our response rates, however, are comparable to other studies with parents of adolescents (38 to $48 \%$ ) [38, 48-51].

Based on the parents that scheduled appointments, interactive scheduling is a feasible strategy both for the parents and clinic. The clinic was able to call responding parents within 2 days and reached most parents on the first attempt. Likewise, the follow through for scheduling appointments when called suggests interactive text messages can be a prompt to help parents enact a plan [52]. Thus, interactive scheduling likely meets the needs of the estimated $10 \%$ of parents who intend to vaccinate their child in the next year, but have not gotten around to it [53]. Our rates of parents requesting a clinic call back in response to the text message (7\%) was comparable to a previous study that allowed parents to respond to text messages indicating needed vaccines (10\%) [18]. For a larger trial, our pilot strategy using interactive scheduling might consider enhancements such as timing text messages more closely to scheduled visits or milestones, completing the scheduling process immediately via text, or targeting optimal times during the week and day to send reminders. 
Phone-based MI using phone numbers from EHR or claims records was acceptable according to parents and feasibly conducted by a trained MINT provider. Our agreement rate of $35 \%$ is comparable with other studies of telephone-based MI that ranged from 26 to 50\% agreement and can be used to help plan sample sizes for future trials $[35,54]$. When compared with physicians trained to perform MI during primary care, our telephone-based approach allowed the use of a highly trained MI provider to conduct the sessions and resulted in the precepts of MI being closely followed. For example, all sessions in our study were highly MI compliant, whereas, in a study of physicians trained to use MI to discuss HPV vaccination, only $28 \%$ of physicians reported using affirmations or reflections more than 75\% of the time [31]. Even highly motivated physicians trained during $6 \mathrm{MI}$ workshops found beginning proficiency for MI difficult to achieve [55]. Additionally, phone-based MI allowed parents more time than likely available during a well child visit to discuss concerns: our average MI conversation of 10 min may be difficult to achieve within a 15 to 20 min well visit [8].

This study has three important limitations. Because it was a feasibility study, we had a small sample: one clinic, one interviewer, and 20 attempted MI interviews. The low sample size prevented us from making meaningful conclusions about effects on vaccination. Future trials can include a larger sample to assess efficacy of the interventions. Second, we did not collect information on what happened during clinic visits (e.g., parent mentioning of reminders or phone calls, physician recommendations, and time spent discussing the vaccine). Thus, we were unable to assess any intermediate effects or potential moderators of the interventions. Third, while we measured delivery of messages, we were unable to assess if messages or phone calls among those who never answered went to the correct person.

This study has three main strengths. First, we used MI as a strategy to reduce parents' HPV vaccine hesitancy and measured interviewer competency with a standardized tool, the MITI. This combination, particularly with phone-based delivery, is novel. Second, we measured feasibility of reminders with a variety of process measures including messages delivered, website hits, and a parent acceptability survey. Third, medical and administrative Medicaid and CHIP records provided reasonably accurate contact information for the parents of 11- to 12-year-old clinic patients.

\section{Conclusions}

Pre-appointment interventions, such as reminder messages and phone-based MI, are feasible strategies to respond to the President's Cancer Panel's goal of increasing parents' acceptance of the HPV vaccine. The positive responses by parents who completed the acceptability survey, the number of visitors to our website, and the in-depth conversations during MI phone calls suggest that the interventions addressed at least some of the needs of parents. Phone-based MI may be a feasible alternative to address the limitations of training physicians in MI as way to reach the parents hesitant to the HPV vaccine. A larger effectiveness trial is warranted and should consider shortening the time between interventions and clinic visits. While evidence suggests that reminder messages are cost-effective [56], future trials should evaluate if the addition of phone-based MI achieves sufficient increases in vaccination to justify the additional expense. Expanding upon the priming effects seen with pre-clinic vaccine reminders [57], if shown effective, more intense pre-clinic interventions like phone-based MI may reduce physician time needed to address parental HPV vaccine hesitancy.

\section{Supplementary Information}

The online version contains supplementary material available at https://doi. org/10.1186/s12889-020-10132-6.

\section{Additional file 1.}

Additional file 2

\section{Abbreviations}

CHIP: Children's Health Insurance Program; HPV: Human papillomavirus; Ml: Motivational Interviewing

Acknowledgements

The authors thank Angela Looney, LPN who scheduled appointments with all text message responders.

\section{Authors' contributions}

SS designed the study, lead the data collection, completed data analysis, interpreted the data, and lead the writing of the manuscript. ER interpreted the data and was a major contributor to the writing of the manuscript. LM helped design the study, conducted the motivational interviews, and helped interpret the data. JB led the text messaging component. LT helped design the study and interpret the data. JK was a major contributor to the content of the messages used for parents. MG helped design the study and interpret the data. AS helped design the study and complete data collection. ES helped design the study and aided data collection. All authors read and approved the final manuscript.

\section{Funding}

Research reported in this publication received financial support from the University of Florida Department of Health Outcomes and Biomedical Informatics. The University and the Department had no role, outside of the involvement of the stated authors, in the design of the study and collection, analysis, and interpretation of data and in writing the manuscript.

\section{Availability of data and materials}

The data that support the findings of this study are available on request from the corresponding author [SS] with a signed data use agreement. The data are not publicly available due to the small sample from one clinic potentially compromising the research participant privacy.

Ethics approval and consent to participate

This study was approved by the University of Florida Institutional Review Board (2015000997). We obtained a waiver of informed consent to send postcard and text message reminders and evaluate the subsequent HPV 
vaccinations. We obtained a waiver of documentation of informed consent for the parent acceptability surveys and the motivational interviews. Parents who participated in the survey indicated their consent by returning the completed survey. Parents verbally consented to participate in the motivational interviews.

\section{Consent for publication}

Not applicable.

\section{Competing interests}

The authors declare that they have no competing interests.

\section{Author details}

'Department of Health Outcomes and Biomedical Informatics, College of Medicine, University of Florida, Gainesville, FL, USA. ${ }^{2}$ The Institute for Child Health Policy, College of Medicine, University of Florida, Gainesville, FL, USA. ${ }^{3}$ Department of Psychiatry, College of Medicine, University of Florida, Gainesville, FL, USA. ${ }^{4}$ Department of Pediatrics, College of Medicine, University of Florida, Gainesville, FL, USA. 'Department of Advertising, College of Journalism and Communication, University of Florida, Gainesville, $\mathrm{FL}$, USA.

Received: 4 June 2020 Accepted: 25 December 2020

Published online: 09 January 2021

\section{References}

1. Rimer B, Harper H, Witte O, Accelerating HPV. Vaccine uptake: urgency for action to prevent cancer; a report to the President of the United States from the President's Cancer Panel. Bethesda: National Cancer Institute; 2014

2. Elam-Evans LD, Yankey D, Singleton JA, Sterrett N, Markowitz LE, Williams $\mathrm{CL}$, et al. National, regional, state, and selected local area vaccination coverage among adolescents aged 13-17 years - United States, 2019. MMWR Morb Mortal Wkly Rep. 2020;69(33):1109-16.

3. Gilkey MB, Calo WA, Moss JL, Shah PD, Marciniak MW, Brewer NT. Provider communication and HPV vaccination: the impact of recommendation quality. Vaccine. 2016;34(9):1187-92.

4. Reiter PL, McRee AL, Pepper JK, Gilkey MB, Galbraith KV, Brewer NT. Longitudinal predictors of human papillomavirus vaccination among a national sample of adolescent males. Am J Public Health. 2013;103(8): 1419-27.

5. Staras SA, Vadaparampil ST, Patel RP, Shenkman EA. Parent perceptions important for HPV vaccine initiation among low income adolescent girls. Vaccine. 2014;32(46):6163-9.

6. Holman DM, Benard V, Roland KB, Watson M, Liddon N, Stokley S. Barriers to human papillomavirus vaccination mong US adolescents: a systematic review of the literature. JAMA Pediatr. 2014;168(1):76-82.

7. Rand CM, Goldstein NPN. Patterns of primary care physician visits for US adolescents in 2014: implications for vaccination. Acad Pediatr. 2018:18(2, Supplement):S72-S8.

8. Gilkey MB, Moss JL, Coyne-Beasley T, Hall ME, Shah PD, Brewer NT. Physician communication about adolescent vaccination: how is human papillomavirus vaccine different? Prev Med. 2015;77:181-5.

9. Bright Futures/American Academy of Pediatrics. Recommendations for preventive pediatric health care: periodicity schedule: American Academy of Pediatrics; 2020. Available from: https://downloads.aap.org/AAP/PDF/ periodicity_schedule.pdf. Cited 2020 December 15

10. Hagan JF, Shaw JS, Duncan PM. Bright futures: guidelines for health supervision of infants, children, and adolescents [pocket guide]. 4th ed. Elk Grove Village: The American Academy of Pediatrics; 2017.

11. McRee A-L, Gilkey MB, Dempsey AF. HPV vaccine hesitancy: findings from a statewide survey of health care providers. J Pediatr Health Care. 2014;28(6):541-9.

12. Francis DB, Cates JR, Wagner KPG, Zola T, Fitter JE, Coyne-Beasley T, Communication technologies to improve HPV vaccination initiation and completion: a systematic review. Patient Educ Couns. 2017;100(7):1280-6.

13. Odone A, Ferrari A, Spagnoli F, Visciarelli S, Shefer A, Pasquarella C, et al. Effectiveness of interventions that apply new media to improve vaccine uptake and vaccine coverage: a systematic review. Hum Vaccin Immunother. 2015;11(1):72-82.

14. Center for Disease Control. The community guide 2019. Available from: https://www.thecommunityguide.org/. Cited 2020 May 7.
15. Jacobson Vann JC, Jacobson RM, Coyne-Beasley T, Asafu-Adjei JK, Szilagyi PG. Patient reminder and recall interventions to improve immunization rates. Cochrane Database Syst Rev. 2018;1.

16. Morris J, Wang W, Wang L, Peddecord KM, Sawyer MH. Comparison of reminder methods in selected adolescents with records in an immunization registry. J Adolesc Health. 2015;56(5):S27-32.

17. Rand CM, Vincelli P, Goldstein NPN, Blumkin A, Szilagyi PG. Effects of phone and text message reminders on completion of the human papillomavirus vaccine series. J Adolesc Health. 2017:60(1):113-9.

18. O'Leary ST, Lee M, Lockhart S, Eisert S, Furniss A, Barnard J, et al. Effectiveness and cost of bidirectional text messaging for adolescent vaccines and well care. Pediatrics. 2015;136(5):e1220-e7.

19. Tull F, Borg K, Knott C, Beasley M, Halliday J, Faulkner N, et al. Short message service reminders to parents for increasing adolescent human papillomavirus vaccination rates in a secondary school vaccine program: a randomized control trial. J Adolesc Health. 2019;65(1):116-23.

20. Hofstetter AM, Vargas CY, Camargo S, Holleran S, Vawdrey DK, Kharbanda EO, et al. Impacting delayed pediatric influenza vaccination: a randomized controlled trial of text message reminders. Am J Prev Med. 2015;48(4):392-401.

21. Stockwell MS, Hofstetter AM, DuRivage N, Barrett A, Fernandez N, Vargas CY, et al. Text message reminders for second dose of influenza vaccine: a randomized controlled trial. Pediatrics. 2015;135(1):e83-91.

22. Kannisto KA, Koivunen MH, Välimäki MA. Use of mobile phone text message reminders in health care services: a narrative literature review. J Med Internet Res. 2014;16(10):e222.

23. Gayes LA, Steele RG. A meta-analysis of motivational interviewing interventions for pediatric health behavior change. J Consult Clin Psychol. 2014;82(3):521.

24. Borrelli B, Tooley EM, Scott-Sheldon LA. Motivational interviewing for parent-child health interventions: a systematic review and meta-analysis. Pediatr Dent. 2015:37(3):254-65.

25. Tripp SB, Perry JT, Romney S, Blood-Siegfried J. Providers as weight coaches: using practice guides and motivational interview to treat obesity in the pediatric office. J Pediatr Nurs. 2011;26(5):474-9.

26. Cushing CC, Jensen CD, Miller MB, Leffingwell TR. Meta-analysis of motivational interviewing for adolescent health behavior: efficacy beyond substance use. J Consult Clin Psychol. 2014:82(6):1212.

27. Lindson-Hawley N, Thompson TP, Begh R. Motivational interviewing for smoking cessation. Cochrane Database Syst Rev. 2015;3.

28. Rollnick S, Miller WR, Butler CC. Motivational interviewing in health care. New York: Guilford Publications; 2008.

29. Fu SS, Roth C, Battaglia CT, Nelson DB, Farmer MM, Do T, et al. Training primary care clinicians in motivational interviewing: a comparison of two models. Patient Educ Couns. 2015;98(1):61-8.

30. Resnicow K, McMaster F, Bocian A, Harris D, Zhou Y, Snetselaar $L$, et al. Motivational interviewing and dietary counseling for obesity in primary care: an RCT. Pediatrics. 2015;135(4):649-57.

31. Reno JE, O'Leary S, Garrett K, Pyrzanowski J, Lockhart S, Campagna E, et al. Improving provider communication about HPV vaccines for vaccine-hesitant parents through the use of motivational interviewing. J Health Commun. 2018;23(4):313-20

32. VanBuskirk KA, Wetherell $\mathrm{J}$. Motivational interviewing with primary care populations: a systematic review and meta-analysis. J Behav Med. 2014; 37(4):768-80.

33. Magill M, Apodaca TR, Borsari B, Gaume J, Hoadley A, Gordon REF, et al. A metaanalysis of motivational interviewing process: technical, relational, and conditional process models of change. J Consult Clin Psychol. 2018;86(2):140-57.

34. Soderlund LL, Madson MB, Rubak S, Nilsen P. A systematic review of motivational interviewing training for general health care practitioners. Patient Educ Couns. 2011;84(1):16-26.

35. Jiang S, Wu L, Gao X. Beyond face-to-face individual counseling: a systematic review on alternative modes of motivational interviewing in substance abuse treatment and prevention. Addict Behav. 2017:73:216-35.

36. Proctor E, Silmere $H$, Raghavan $R$, Hovmand $P$, Aarons G, Bunger A, et al. Outcomes for implementation research: conceptual distinctions, measurement challenges, and research agenda. Adm Policy Ment Health. 2011:38(2):65-76.

37. Eldridge SM, Chan CL, Campbell MJ, Bond CM, Hopewell S, Thabane L, et al. CONSORT 2010 statement: extension to randomised pilot and feasibility trials. BMJ. 2016;355:i5239. 
38. Staras SA, Vadaparampil ST, Livingston MD, Thompson LA, Sanders AH, Shenkman EA. Increasing human papillomavirus vaccine initiation among publicly insured Florida adolescents. J Adolesc Health. 2015;56(5 Suppl):S40-6.

39. Miller WR, Rollnick S. Motivational interviewing: helping people change. New York: Guilford Press; 2012.

40. Aazh $\mathrm{H}$. Feasibility of conducting a randomized controlled trial to evaluate the effect of motivational interviewing on hearing-aid use. Int J Audiol. 2016:55(3):149-56.

41. Yahne C, Jackson S, Tollestrup K. Training teen mothers as motivational interviewers: a feasibility study. MITRIP. 2014;1(3):25-30.

42. O'Kane C, Irwin JD, Morrow D, Tang L, Wong S, Buchholz AC, et al. Motivational interviewing with families in the home environment. Patient Educ Couns. 2019;102(11):2073-80.

43. Chen J, Li X, Xiong Y, Fennie KP, Wang H, Williams AB. Reducing the risk of HIV transmission among men who have sex with men: a feasibility study of the motivational interviewing counseling method. Nurs Health Sci. 2016; 18(3):400-7.

44. Moyers TB, Rowell LN, Manuel JK, Ernst D, Houck JM. The motivational interviewing treatment integrity code (MITI 4): rationale, preliminary reliability and validity. J Subst Abuse Treat. 2016;65:36-42.

45. Richman AR, Maddy L, Torres E, Goldberg EJ. A randomized intervention study to evaluate whether electronic messaging can increase human papillomavirus vaccine completion and knowledge among college students. J Am Coll Health. 2016;64(4):269-78.

46. Gerend MA, Stephens YP, Kazmer MM, Slate EH, Reyes E. Predictors of human papillomavirus vaccine completion among low-income Latina/o adolescents. J Adolesc Health. 2019;64(6):753-62.

47. Hofstetter AM, Vargas CY, Kennedy A, Kitayama K, Stockwell MS. Parental and provider preferences and concerns regarding text message reminder/ recall for early childhood vaccinations. Prev Med. 2013;57(2):75-80.

48. Dempsey AF, Pyrzanowski J, Lockhart S, Campagna E, Barnard J, O'Leary ST. Parents' perceptions of provider communication regarding adolescent vaccines. Hum Vaccin Immunother. 2016;12(6):1469-75.

49. Opel DJ, Taylor JA, Mangione-Smith R, Solomon C, Zhao C, Catz S, et al. Validity and reliability of a survey to identify vaccine-hesitant parents. Vaccine. 2011;29(38):6598-605.

50. VanWormer JJ, Bendixsen CG, Vickers ER, Stokley S, McNeil MM, Gee J, et al. Association between parent attitudes and receipt of human papillomavirus vaccine in adolescents. BMC Public Health. 2017;17(1):766.

51. Brabin L, Roberts SA, Farzaneh F, Kitchener HC. Future acceptance of adolescent human papillomavirus vaccination: a survey of parental attitudes. Vaccine. 2006;24(16):3087-94.

52. Milkman KL, Beshears J, Choi JJ, Laibson D, Madrian BC. Using implementation intentions prompts to enhance influenza vaccination rates. Proc Natl Acad Sci U S A. 2011;108(26):10415-20

53. Brewer NT, Gottlieb SL, Reiter PL, McRee AL, Liddon N, Markowitz L, et al. Longitudinal predictors of human papillomavirus vaccine initiation among adolescent girls in a high-risk geographic area. Sex Transm Dis. 2011;38(3): 197-204.

54. Young DR, Nguyen MK, Yamamoto A, Pomichowski M, Cornejo M, Paz S, et al. Telephone-based motivational interviewing versus usual care in primary care to increase physical activity: a randomized pilot study. Pilot Feasibility Stud. 2019;5:6

55. Mullin DJ, Forsberg L, Savageau JA, Saver B. Challenges in developing primary care physicians' motivational interviewing skills. Fam Syst Health. 2015;33(4):330-8.

56. Spencer JC, Brewer NT, Trogdon JG, Weinberger M, Coyne-Beasley T, Wheeler SB. Cost-effectiveness of interventions to increase HPV vaccine uptake. Pediatrics. 2020;146(6):e20200395.

57. Staras SAS, Vadaparampil ST, Thompson LA, Scherr C, Gurka MJ, Filipp SL, et al. Postcard reminders for HPV vaccination mainly primed parents for providers' recommendations. Prev Med Rep. 2020;20:101188.

\section{Publisher's Note}

Springer Nature remains neutral with regard to jurisdictional claims in published maps and institutional affiliations.

\section{Ready to submit your research? Choose BMC and benefit from:}

- fast, convenient online submission

- thorough peer review by experienced researchers in your field

- rapid publication on acceptance

- support for research data, including large and complex data types

- gold Open Access which fosters wider collaboration and increased citations

- maximum visibility for your research: over $100 \mathrm{M}$ website views per year

At BMC, research is always in progress.

Learn more biomedcentral.com/submissions 